The Journal of

Thoracic and Cardiovascular

Surgery

Vol 127, No. 4, April 2004

\title{
Leonardo da Vinci as a paradigm for modern clinical research
}

\author{
F. C. Wells, MA, MS, FRCS, FEACTS, and T. Crowe, MA ${ }^{\mathrm{b}}$
}
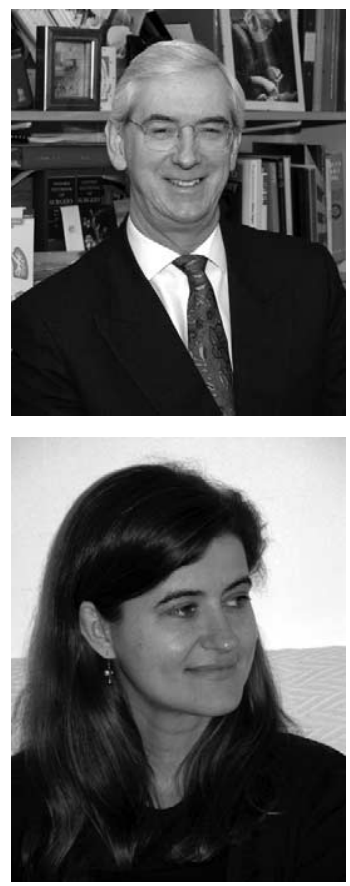

Wells (top) and Crowe

From the Department of Cardio-thoracic Surgery, Papworth Hospital, ${ }^{\text {a }}$ Cambridge, and The Universal Leonardo Bureau, Central Saint Martins College of Art and Design, ${ }^{\mathrm{b}}$ London, United Kingdom.

Received for publication Feb 4, 2004; accepted for publication Feb 10, 2004.

Address for reprints: Mr Francis C. Wells, Department of Cardiothoracic Surgery, Papworth Hospital, Papworth Everard, Cambridge CB3 8RE, United Kingdom (Email: francis.wells@papworth.nhs.uk).

J Thorac Cardiovasc Surg 2004;127:929-44

$0022-5223 / \$ 30.00$

Copyright (C) 2004 by The American Association for Thoracic Surgery

doi:10.1016/j.jtcvs.2004.02.002
In the normal course of events many men and women are born with various remarkable qualities and talents; but occasionally, in a way that transcends nature, a single person is marvellously endowed by heaven with beauty, grace, and talent in such abundance that he leaves other men far behind, all his actions seem inspired, and indeed everything he does clearly comes from God rather than from human art.

-Giorgio Vasari. Lives of the Painters, Sculptors and Architects, 1568

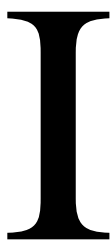

$\mathrm{s}$ it possible that a self-educated man born 552 years ago this month could have anything to teach us about the conduct of modern clinical research? Those who are familiar with his achievements know that he is commonly described as a "man ahead of his time." Not only is this statement true of his contributions to painting, sculpture, and architecture, but also in engineering, military science, botany, geology, geography, hydraulics, aerodynamics, optics, and, of special interest to us, anatomy. Equally as impressive as the industry that Leonardo demonstrated in undertaking all of this work are his methods of investigating new ideas, many of which were truly ahead of their time.

The aim of this article is to demonstrate that the scientific methods of deduction and experimentation employed by Leonardo remain pertinent today. His ability to investigate a vast range of subjects by meticulous observation, rational thought, and teleological deductive reasoning, associated with a divine gift for drawing, produced anatomical and physiological revelations, elements of which remain relevant now. By applying rigorous contemporary methods of logic and rhetoric, he was able to derive important ideas and truths that were not recognized in his own time. Many of these deductions can only be properly appreciated in the light of current knowledge. Leonardo was greatly admired in his own time and his artistic and engineering services were greatly sought after, both at home and abroad. However, so far as we know, little or none of his anatomical and physiological studies had any impact on the general science of the day. Conflict between Leonardo and the acknowledged academics of his time may have been the reason for much of the lack of recognition of the scientific value of his work. Indeed, it is only in the past 150 years that serious study has revealed the vitality and depth of his understanding and knowledge.

On careful inspection of the notes and drawings, it is possible to identify the application of Aristotelian syllogistic logic and Renaissance rhetoric. The application of these methodologies within the strict discipline of the contemporary rules of usage allowed the investigator to derive new ideas that could then be subjected to scientific testing. The regressus demonstrativus is an analytical method that was accepted and used during Leonardo's time. It consisted of two important steps. The 
first step was the derivation of a "reasoned fact" by deductive thought. The second step consisted of "demonstrating" this fact by experimental method. This can be related to today's philosophy of scientific thought that teaches us to question accepted scientific knowledge and then to establish new knowledge through the practice of scientific method. Whether Leonardo used the regressus demonstrativus in a planned and informed way is difficult to confirm, but the ebb and flow of self-criticism and analysis found within his notebooks lead the reader to associate this method with his work.

\section{His Early Development}

Leonardo da Vinci was born the illegitimate son of Ser Piero da Vinci, a Florentine notary, and a local village girl of lower class, Caterina. His birthplace was Anchiano, a hamlet in the hills above the small Tuscan town of Vinci, west of Florence. The birth is recorded in local records as taking place on Saturday, April, 15, 1452, at 10.30 PM. This inauspicious start dictated so much of what followed in his life. Leonardo was taken into his father's house an unknown time after his birth. He seems to have been cherished by his elderly grandparents, Antonio and Lucia. Antonio was 80 years of age at Leonardo's birth. His uncle Francesco, his father's younger brother, also lived there and became very close to the young Leonardo.

Birth outside marriage conferred disadvantages that would particularly affect the young Leonardo in a way that may have shaped much of his life. Illegitimate children were not totally ostracized from middle class society, but access to a classical education was very restricted. Entry to university was barred and there was no hope of joining any of the respected professions such as law or medicine. The respective professional guilds specifically forbade it. As a result, Leonardo was not taught Latin, Greek, or mathematics in his schooling. These subjects, important in the Renaissance, would have to be studied later in his life, driven by his insatiable appetite for "true knowledge." This lack of a classical education also meant that Leonardo was regarded with great skepticism by the academics of the day, a constant source of irritation to him. He wrote:

Though I may not, like them [establishment scholars in general], be able to quote other authors, I shall rely on that which is much greater and more worthy: on experience, the mistress of their Masters. They go about puffed up and pompous, dressed and decorated with [the fruits], not of their own labours, but of those of others. And they will not allow me my own. ${ }^{1}$

\section{Codex Atlanticus, 115 a}

Leonardo's career in the arts began when he left his Vinci home and moved to Florence. This was probably between the ages of 12 and 14 years. At that time his father had arranged for him to be taken into the most highly regarded workshop in Florence, that of Andrea del Verrocchio. Ser Piero probably knew the great artist personally. Leonardo had exhibited outstanding artistic talent from an early age and it is likely that his father would have shown Verrocchio work completed by his son. Sadly there are no known works by him from this period in his life. The earliest known drawing by the young Leonardo is dated 1469 (aged 17, perhaps the age at which he entered Verrocchio's studio).

It appears that the young Leonardo rapidly made an impression on his master, as he seems to have made with all who came in contact with him. Vasari described Leonardo as "an artist of outstanding physical beauty who displayed infinite grace in everything he did and who cultivated his genius so brilliantly that all problems he studied he solved with ease." 2

Whilst working on "The Baptism of Christ," begun by Verrocchio, who executed the two principal figures, Christ and St John the Baptist, the master was reported to be so overwhelmed by the artistic skill of his young pupil, Leonardo, who painted the angel to the left of the picture, that he swore never to pick up a paintbrush again! $!^{3,4}$ This awareness of his pupil's superior ability seems not to have engendered jealousy but rather admiration and a fostering of his great gifts. Leonardo in his turn appears to have been aware of this and later remarked in an entry in one of his notebooks, "He is a poor disciple who does not excel his master." 5

In coming to an understanding of how Leonardo managed to master so many areas of expertise, it is important to recognize that such workshops as the one in which he was apprenticed did not simply deal in the production and teaching of painting and sculpture, but included aspects of engineering, architecture, and metalwork (Verrocchio was responsible for the orb that crowns the Duomo in Florence). It is likely that Leonardo's abiding and ever more absorbed interest in the human body was triggered by the teaching of human and animal anatomical studies within the studio. What would have begun as a desire for accurate representation of the human form became an obsession for total knowledge of the working of the body, constantly relating its structure to its function. This pluripotential workshop environment would have been the perfect environment in which to cultivate an uninhibited and lateral-thinking mind.

Florentine civic records show that Leonardo was admitted to the Florentine guild of painters, the Compagnia di San Luca, in 1472. It is likely that Verrocchio thought highly of his gifted pupil as he retained him as a collaborator for 5 years after Leonardo's admission to the guild, and in 1476 he is mentioned as living with Verrocchio. ${ }^{6}$

Although his skills as an artist are widely known, it is perhaps less well recognized that he had significant talents 
as a musician. He was recognized as being accomplished with the lira da braccio, a 7-stringed, bowed instrument that was a forerunner of the modern violin, which he is reported to have played beautifully. Indeed, he is credited by some to be the inventor of a very early form of violin. When he left Florence to embark on his first Milanese period he took with him an instrument fashioned from the skull of a horse as part of an attempt to persuade the Duke of Milan to take him into his court.

His skills as an inventor of fantastic machines and weapons of war, both defensive and aggressive, were widely known and sought after. He was also known for his skills as a cartographer and architect and for his interest in public health matters. The latter was no doubt fuelled by the regular visitation of the plague to communities during this period. Indeed, in his search for patronage and success, Leonardo's endeavors appear to have strayed into many areas, several of which he worked on at the same time. Perhaps he had the classical "surgical mind," characterized by intense concentration on the job in hand, only to be rapidly overtaken by new thoughts and ideas as the first loses interest or reaches a point where it is complete for the moment as in a surgical procedure.

His interest in scientific method was underpinned by a desire to set everything in a mathematical construct. Just as statistical method is vital to the conduct of good research today, so the importance of mathematics and mathematical method was to Leonardo. Quite early he recognized this need and wrote, "He who debases the supreme certainty of mathematics feeds on confusion and can never silence the contradictions of the sophistical sciences" (W 19084r). ${ }^{7} \mathrm{He}$ also stated, "... There is no certainty in sciences where one of the mathematical sciences cannot be applied or which are not associated with mathematics" (MS G.17r). ${ }^{8}$

Although it seems clear that whilst Leonardo was widely known and probably respected during his lifetime, as alluded to earlier, his seriousness from a traditional academic point of view was very much in question. We know this because of comments made by him regarding the constrictive nature of perceived and received knowledge. However, irrespective of contemporary academic criticism, it is clear from so much of his writing that rigorous scientific method was central to his thinking. Merely repeating what others before him had thought was never enough for him. Although there is evidence in his notebooks of his acceptance of many perceived truths such as Galenic anatomy, the hallmark of Leonardo is that he challenged these perceptions at some time in his life. Indeed, in his notebooks he noted, "Science is the Captain and practice the soldiers" (I2 $82 \mathrm{a}){ }^{9}$ neatly encapsulating the concept of rigorous research always supported by intense industry in pursuing the answer to any question.
What then of his method of working, and can it be referred to as "scientific" in the modern sense? When his notebooks are inspected carefully, several methods appear to be in operation. First, there is a constant questioning of thoughts and ideas, a kind of personal rhetoric, as if exercising his deductive and logical powers. Second, there is the recurring evidence of the power of drawing over the written word despite the fact that he wrote extensively on so many subjects. Third is the concise nature of dealing with a subject often on a single page of his notebook. This is made possible by the divine skill that he possessed in drawing (Figure 1).

His deductive reasoning is characterized by intense observation backed up by considerable powers of lateral thinking, which were born of an amazing diversity of interests, but criticized by many as being mercurial in attitude. It is interesting to speculate whether he would have achieved a fraction of what he accomplished without this ability to rapidly move from one form of investigation to another. Although annoying to students of his work, it may be that this apparent inability to complete things was a strength that gave him an immense breadth of knowledge, which he was capable of employing when needed.

From the form of his writing it would appear that experimentation was an important part of the process, although in his anatomical studies there are few concrete examples of this. It appears that he was able to make use of a great facility to use sensory data. The constant linking of structure to function in his anatomy and physiology set him apart from others at that time, and for some considerable time to come (Figure 2). Teleology may be defined as the doctrine or study of ends or final causes as related to the evidence of design or purpose in nature. Teleological description not only characterizes much of his work, but also appears to have informed him of an appropriate line of questioning and pointed him toward answers that were not only correct but also beautiful in their analysis. This form of analysis is frequently criticized by contemporary academia, but it is irrefutably useful when deriving an understanding of observations in nature. A teleological approach, combined with the easy transference of observed phenomena in nature to questions in anatomy and physiology, allowed this remarkable man to derive extraordinary deductions. This we will see in the way he related his knowledge of hydrodynamics to the problem of aortic valve function.

As time passed, Leonardo became more and more absorbed with the concept that there must be unifying precepts in the natural world that extended from the body of the earth to the cosmos. Sitting squarely in the middle of this continuum seemed to be man. Therefore, to take observed truths from the natural world and to apply them to questions that he was investigating in the body seemed only natural. A wonderfully complete example of this is the method by 


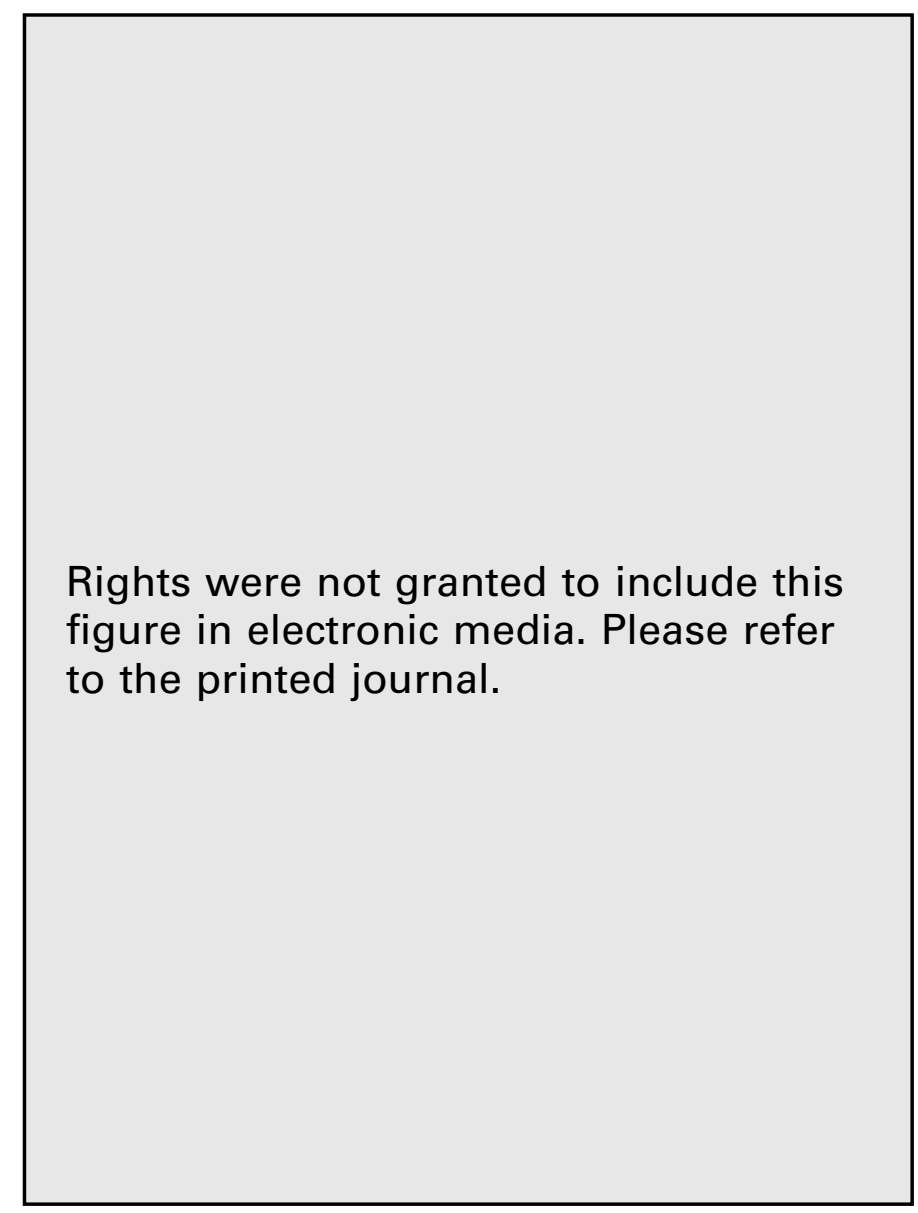

Figure 1. Royal Library, Windsor 19074v. Mechanism of the ventricles of the heart. Two drawings of the heart, probably an ox. Pen and ink on blue paper. On this page at top right is a sketch of the lines of incision in the ventricles to expose the internal anatomy and an intricate dissection of the coronary arteries. At bottom right, the right coronary artery has been drawn to show its branching and diminution in size of the vessels as they branch. There is also a very fine mechanical drawing to show the action of the atrioventricular valves. (The Royal Collection ${ }^{\odot}$ 2004, Her Majesty Queen Elizabeth II.)

which he described the closure mechanism of the aortic valve using his knowledge of hydrology and fluid dynamics. We will return to this in detail in due course.

There are three periods of study of anatomy in Leonardo's life. The first was from 1487 to 1495 whilst in Milan. This period appears to be heavily influenced by Galenic thought (Figure 3), although a lot of his anatomy at that time was very accurate and beautiful (Figure 4). The second was from 1504 to 1509. At this time there was a continued reliance on Galen's precepts, but a singular event appears to have begun to significantly shift his thoughts. That was the observation of the death of a centenarian in the Santa Maria Nuova hospital in Florence. He describes "a death so sweet" in this man who had suffered no ill feelings (Figure 5). It was as a result of the rapid dissection of this male corpse that he composed a wonderful description of the basic morbid anatomy of what we refer to today as atherosclerosis.
And this old man, a few hours before his death, told me that he had passed 100 years, and that he was conscious of no failure of body, except feebleness. And thus sitting upon a bed in the hospital of Santa Maria Nuova at Florence, without any untoward movement or sign, he passed away from this life. And I made an anatomy to see the cause of a death so sweet, which I found to proceed from debility through lack of blood and deficiency of the artery, which nourishes the heart and the lower members. I found this artery very desiccated, shrunken and withered .... the other anatomy I made was of a child of 2 years in which I found everything to be the opposite to that of the old man.

Windsor $19027 v^{10}$

(Figure 6, $A$ and $B$ ) 


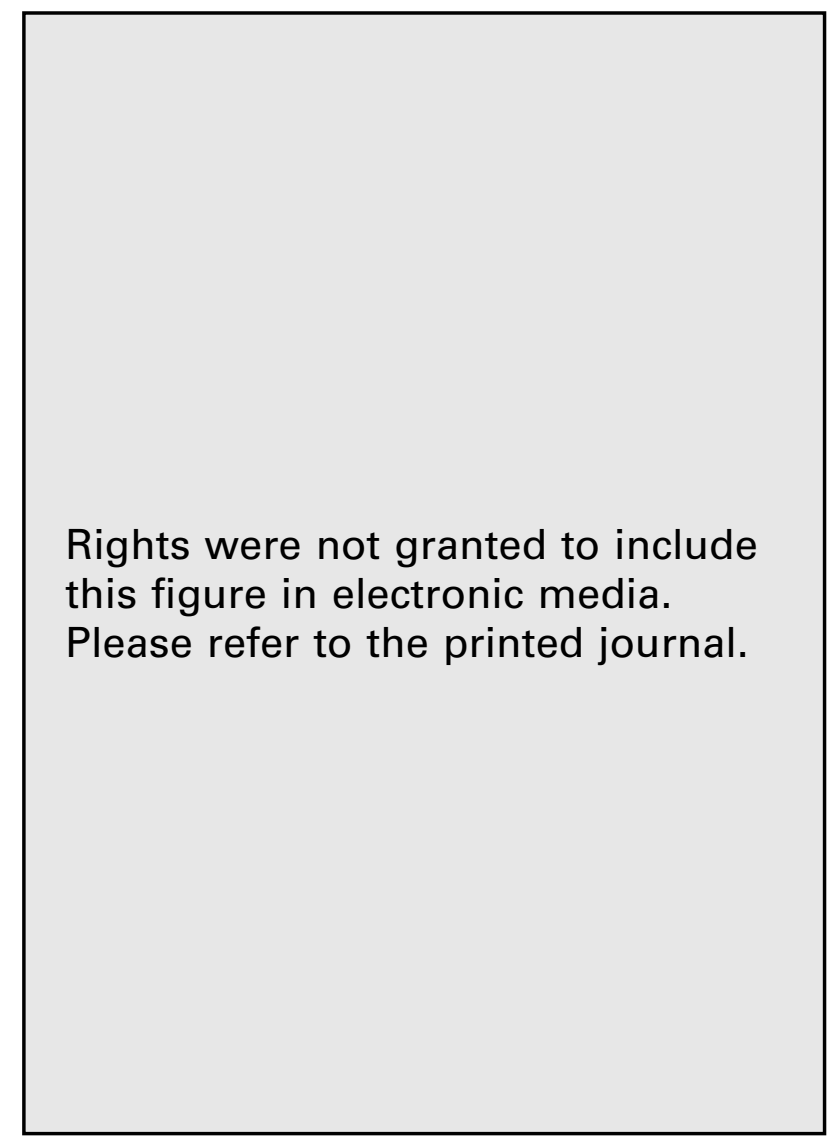

Figure 2. Royal Library, Windsor 19057r. The skull sectioned, 1489. Two drawings of the skull from the left. In his notes he writes, "Where the line $a m$ intersects the line $c b$ will be the confluence of the senses, otherwise known as the "sensus communis." This work reflects Leonardo's recognition of the brain as the center of "life," in keeping with modern brain death criteria. Prior to this, the heart had been regarded as the "seat of the soul." (The Royal Collection ${ }^{\odot}$ 2004, Her Majesty Queen Elizabeth II.; photographer: EZM.)

Note here not only the precise reporting of the keen observation, but the accuracy of the deductions that are made by Leonardo. This wonderful observation is then supported by further observations on the same page of notes by Leonardo:

...the tunics of the vessels behave in man as in oranges, in which the peel thickens and the pulp diminishes the older they become. And if you say that it is the thickened blood which does not flow through the vessels, this is not true, for the blood does not thicken in the vessels because it continually dies and is renewed." 10

Then as if to prejudge our knowledge of the role of the endothelium in atherosclerosis he says, "I judge that a structure which is nearer to its source of nourishment, grows the more; and for this reason these vessels being the sheath

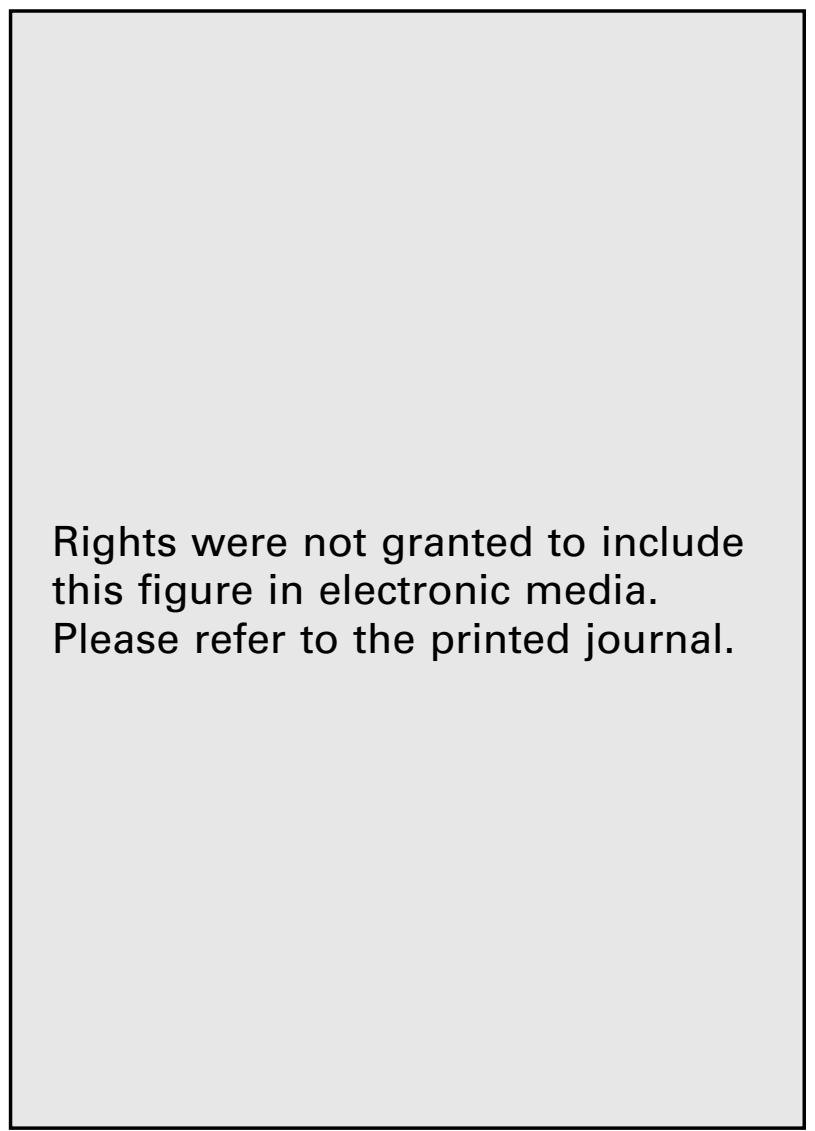

Figure 3. Royal Library, Windsor 12597. Anatomical figure showing heart, liver, and main arteries. Pen and ink over black chalk with green wash. Note the liver drawn as a sprouting of a seed. The head and neck vessels are ungulate and those to the lower limbs in the manner of Mundinus and Avicenna. (The Royal Collection ${ }^{\odot}$ 2004, Her Majesty Queen Elizabeth II; photographer: EZM.)

for the blood which nourishes the body, it nourishes the veins in proportion to their proximity to the blood" (Windsor $19028 \mathrm{v}){ }^{11}$

In this passage, Leonardo both accurately described what he saw and used his knowledge regarding the "renewal of blood" to draw the correct conclusions. This remarkable passage reveals his very modern thought on the effects of aging on the vessel wall followed by brilliant deductions on the continuous renewal of the blood. Whether the "renewal" that he referred to is the passage of flowing blood through the vessels or the continuous regeneration of the components of the blood is in one sense irrelevant. If he meant that interruption to flow would lead to coagulation, this is profound, as it predates the work of John Hunter and Virchow, who are generally accredited with the original observations on the clotting of blood and the importance of continuous flow to prevent this. If he was alluding to the regeneration of the components of the blood, then he was drawing 


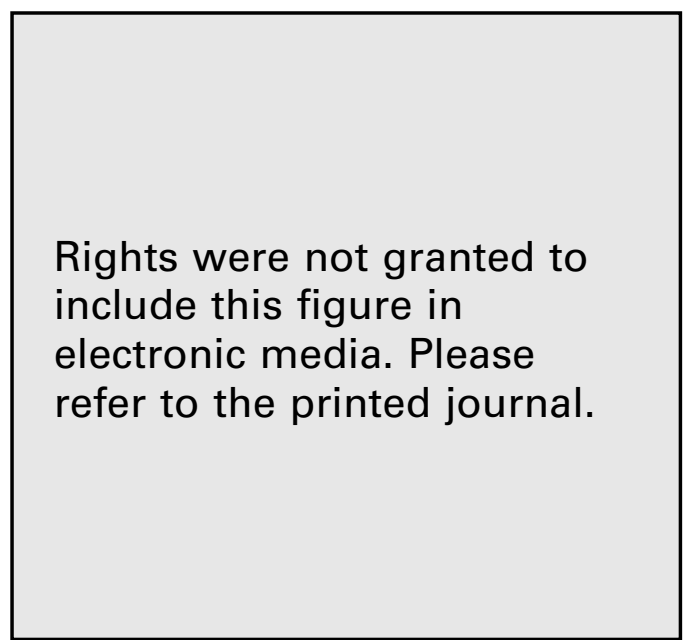

Figure 4. Royal Library, Windsor 19058r. The skull sectioned. A skull viewed obliquely from above and the left to show, probably for the first time, the middle meningeal artery. (The Royal Collection ${ }^{\odot}$ 2004, Her Majesty Queen Elizabeth II; photographer: EZM.)

conclusions that antedate the discovery of the components of the blood that have to await the work of Hooke, Leeuwenoek, and others with the discovery of the microscope. Whichever was in his mind whilst writing this passage, dramatic though it is in its own right, it still is dwarfed by the correct conclusion with regard to the cause of the reduced blood flow to an organ in old age, the thickening and tortuosity of the vessel walls, now known as atherosclerosis.

His third anatomical period began in 1509 when he left Milan. This marks a distinct move away from remaining Galenic influence to a more confident record of his own interpretation and representation of his own observations and deductions. In these latter years it would seem that he had had some form of association with the professor of anatomy first in Pavia and then in Padua, Marcantonio della Torre (c.1479-1511). It is likely that it was a very shortlived relationship, as they are reported to have met in 1510 , just 1 year before Marcantonio died of the plague.

If we compare the Leonardo anatomical illustrations with others of the period, the difference is vast. We can see in Leonardo's work clearly recognizable anatomy that is beautiful and, above all, correct. The beauty and the power of Leonardo's anatomical drawings was witnessed by William Hunter who, on seeing them for the first time in 1773, wrote in a letter to Albrecht von Haller, the great physiologist: “... I expected to see little more than such designs in anatomy as may be useful for a painter in his own profession, but I saw and indeed with astonishment that Leonardo had been a general and a deep student. I am fully persuaded that Leonardo was the best anatomist in the world at that time." 12 He was so impressed that he intended to publish them. However, he was prevented from doing so by his death in 1783.

As witnessed by Hunter, the drawings are captivating and astonishingly correct, but many of the written deductions relating form to function are nothing less than a work of genius when one considers the state of general scientific knowledge of the time. How was this achieved? We have alluded to the use of deductive reasoning within the rigor of the methods laid out in the regressus demonstrativus. The following passages will endeavor to set out the method of this reasoning process.

\section{Regressus Demonstrativus Employed for Anatomical Study}

In general, practical, precise data of human physiology could only be obtained by investigators at the time with very simple methods of measurement of size, mass, color, consistency, smell, and taste, coupled with very keen observation. To make a well-considered (scientific) arrangement of these sensory data (observational), the investigator had to be guided by more or less fixed rules that could be uniformly applied. This form of protocol would allow a common understanding and dissemination of knowledge.

In the Renaissance, the problem of what the correct analytical method should be was hotly debated. Indeed, the use of correct scientific method within clinical surgery remains controversial today. ${ }^{13}$ Several authors have noted that Leonardo was well aware of these discussions and almost certainly took part in them, as witnessed by some of his comments. ${ }^{14,15}$

Among the scientific procedures discussed in Italy in the 15th century, the most important was perhaps the Regressus Demonstrativus. In this pattern of analysis an inference from an observed effect to its proximate (most closely related) cause was combined with an inference from the proximate cause to the observed effect. Jacopo Zabarella (1533-1589) gave the most elaborate and influential version of this method in his treatise De Methodis. ${ }^{16}$ According to him, there were only two scientific methods, the demonstration of the "reasoned fact" (that is, deduction of underlying laws from observed effects; reasoning or demonstratio propter quid or the methodus compositiva), and the demonstration of the "fact" (that is, explanatory synthesis of effects on the foundation laws; demonstratio quod, or the methodus resolutiva). It was reasoned that to know the "substance" and "properties" of natural things is everything that we needed to know about them; the resolutive method gives the definition of the substance (fact), and the compositive method, the properties (reasons for the fact).

These two scientific methods are based on two kinds of syllogisms mentioned in Aristotle's Analytica Posteriora in his discussion demonstrating that something "is" the case and demonstrating "why" something is the case. A slightly expanded example from Aristotle's Analytica can serve as 
Rights were not granted to include this figure in electronic media. Please refer to the printed journal.

Figure 5. Royal Library, Windsor 19005r (detail). Superficial muscles and veins of the arm. Drawing, almost certainly, of the centenarian who was the subject of dissection by Leonardo. Also shown is the lower jaw. (The Royal Collection () 2004, Her Majesty Queen Elizabeth II; photographer: EZM.)

an illustration. A proof a priori would go as follows: "Heavenly bodies that are near the earth do not twinkle; The planets are near the earth; Hence the planets do not twinkle." Corresponding proof a posteriori is then: "Heavenly bodies that are near the earth do not twinkle; The planets do not twinkle; The planets are near the earth."

The compositive argument is a proof a priori. In the middle term (the planets are near the earth) lies the "reason" for the major statement: the planets do not twinkle. The resolutive argument is a proof a posteriori; the middle term gives the "effect" (the observed phenomenon: the planets do not twinkle) instead of the reason. The purpose in using these syllogisms is not to acquire new knowledge but to attain a higher degree of scientific certainty. New knowledge came from keen observation and teleological deductive reasoning.

The resolutive and compositive methods are therefore two phases of the regressus demonstrativus, and both have to be completed for us to obtain robust scientific certainty. Hence here we have one syllogism based on an observed fact (planets are near the earth) and the other on the reasoned fact (planets do not twinkle). This gives us knowledge of the "what" and knowledge of "the cause," respectively.

Aristotelian epistemological writings also recognized the distinction between the order of knowledge and the order of nature, as well as the order in which we know things and their natural order. He recognized that qualities perceptible by the senses are immediately known to us, unlike natural causes which, in nature, bring about their effects, which make them known to us. This is something that we can only reconstruct afterward and may lead the investigator toward teleological doctrine.

As a result of this distinction, Renaissance philosophers argued that one should reason from "effect" to proximate

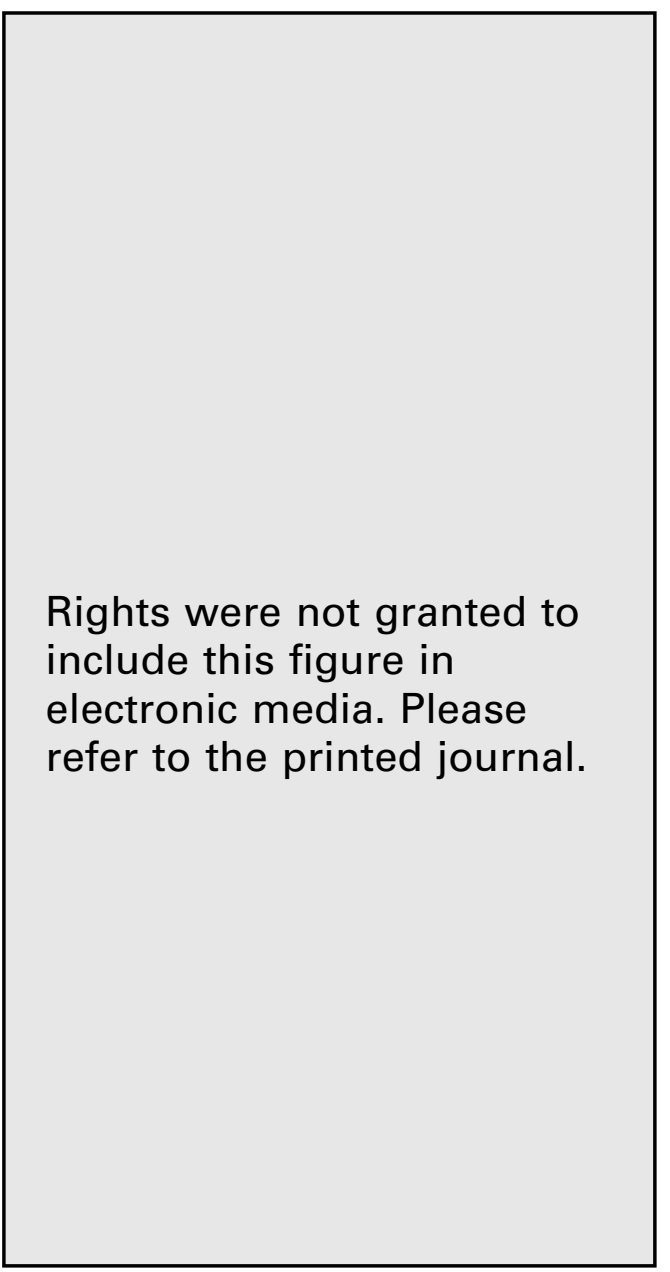

Figure 6. A, Royal Library, Windsor 19027r (detail). The superficial veins in the left arm, and the vessels of the young and old. B, Windsor 19028v (detail). The portal and celiac veins and the blood vessels of the kidneys, liver, and spleen. Drawings to show the tortuosity of the arteries of the arm and the superior mesenteric arteries. In part $A$ can be seen the comparison of the vessels of the old man on the left and the straight vessels of the child that he compares them to. (The Royal Collection ${ }^{\circ}$ 2004, Her Majesty Queen Elizabeth II.)

cause and from proximate cause to reasoned "fact." Sensory perception, or the unmediated experience of nature, is therefore just as important as "a priori" inference in the regressus demonstrativus method.

This form of Aristotelian reasoning was known and used by Leonardo and appears in his notebooks. (Codex Arundel, f.82). ${ }^{17}$ In his treatise on the eye he referred to sometimes drawing conclusions about effects from causes and sometimes about causes from effects. Leonardo's use of this method of analysis will be demonstrated below in a fuller discussion of this interpretation of aortic valve function.

Underpinning all of his deductive reasoning, Leonardo possessed the wonderful ability to record his observations 


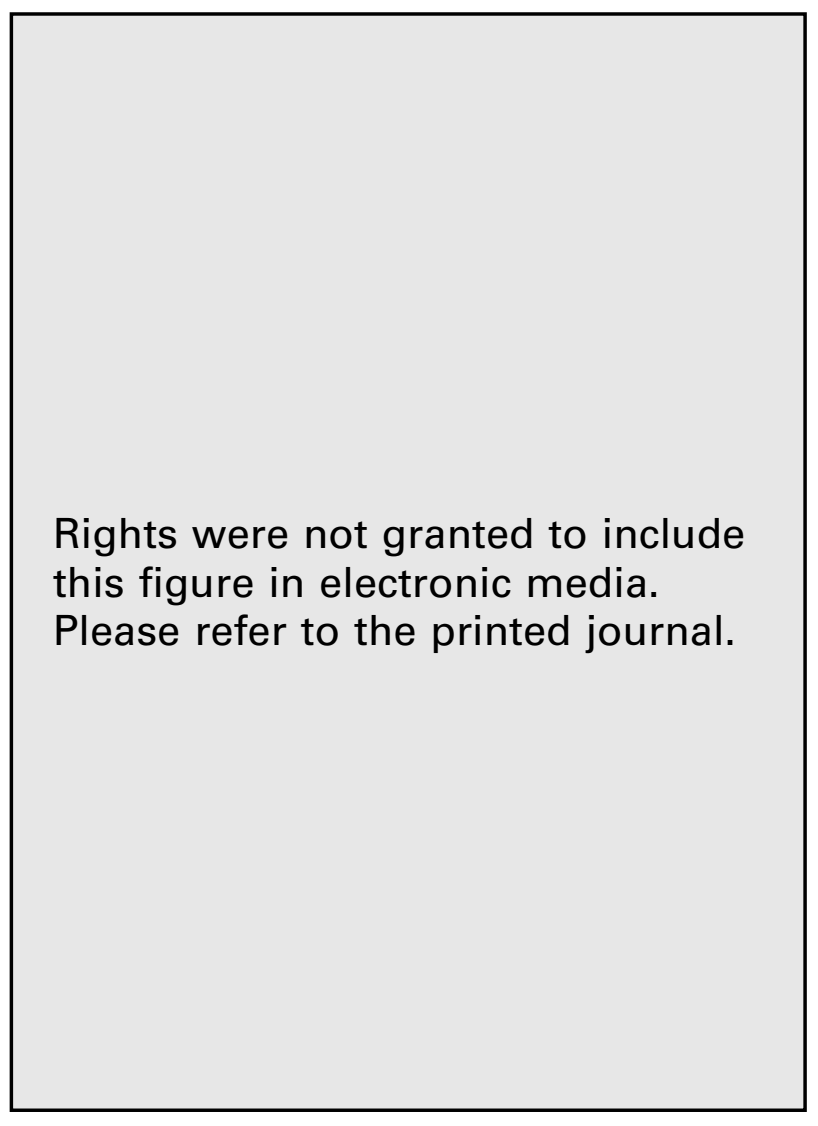

Figure 7. Royal Library, Windsor 12625. A comparison of the legs of man and horse. In another note he demands the dissection of the legs of a frog as the muscles and bones so closely resemble those of man. Note also the muscles reduced to cords to represent more clearly their mechanical function. (The Royal Collection ${ }^{\odot}$ 2004, Her Majesty Queen Elizabeth II; photographer, EZM.)

visually with a series of anatomical drawings that have not been surpassed for their beauty. It is important to recognize that many of the drawings represent anatomy of animals other than man and in some cases seem to represent a merging of anatomy from both animal and man (Figure 7). This has led to criticism of accuracy by some authors who have perhaps missed this important subtlety, but as will be elucidated later, this practice may have allowed Leonardo to make progress in the understanding of the part under inspection. For example, certain structures in the ox are frequently easier to dissect and see than in man. In addition, it would have been far less complicated to gain access to material from an animal than a human.

The way in which Leonardo made different types of drawings for different purposes is also important to note. In the following passage he draws attention to the fact that much more can be gained from a drawing that illustrates both function and structure.
And you, who say that it would be better to watch an anatomist at work than to see these drawings, you would be right, if it were possible to observe all the things which are demonstrated in such drawings in a single figure, in which you, with all your knowledge of more than some few veins, to obtain a true and perfect knowledge of which I have dissected more than ten human bodies ... this I repeated twice, to learn the difference.

$$
\text { Windsor An IV. } 167 a^{18}
$$

Here he makes the point that he was amalgamating ideas and understanding from several dissections into one drawing. He was not simply drawing what he saw in every case. There was a considerable amount of integration of perception and ideas. Some of these drawings illustrate the surface of a structure, others represent a transparency of the organ, and others relate one structure to another and may be very simplified. Several of these techniques can be seen in one drawing. An example of this is the whole body drawing of a female (Figure 8). In this drawing the thyroid gland is drawn as a solid organ and only its surface is shown. The uterus is drawn as a transparent structure. The pulmonary veins entering the heart look as if they are entering the right atrium, but that is because they have not been dissected and are illustrated as viewed from the anterior view without dissection. The section of the heart drawn, however, demonstrates the ventricular chambers in the plane of section used. Many other drawings are illustrations for evolving thoughts and may not be intended as accurate likenesses.

The power of drawing to convey information is propounded many times by Leonardo in the notebooks. In the following passage he emphasizes this point.

With what words, o writer, will you describe with like perfection the entire configuration which the drawing here does? Lacking knowledge this you describe confusedly and leave little conception of the true shape of things, which you, in self-deception make believe that you can fully satisfy your auditors when you must speak of the configuration of some bodily structure bounded by surfaces. But I council you not to encumber yourself with words unless speaking to the blind. He goes on to say, "with what words will you describe this heart so as not to fill a book? The longer you write on the details the more you will confuse the mind of the auditor."

$$
\text { Windsor } 19071 r^{19}
$$

Drawing therefore became a means of explanation for him, as well as representation of the structure under investigation. There are many examples of this in the manuscripts. His rendering of the mitral valve as a quadri-leaflet structure antedates our better understanding of the valve leaflets. The deep scalloping of the posterior leaflet is 


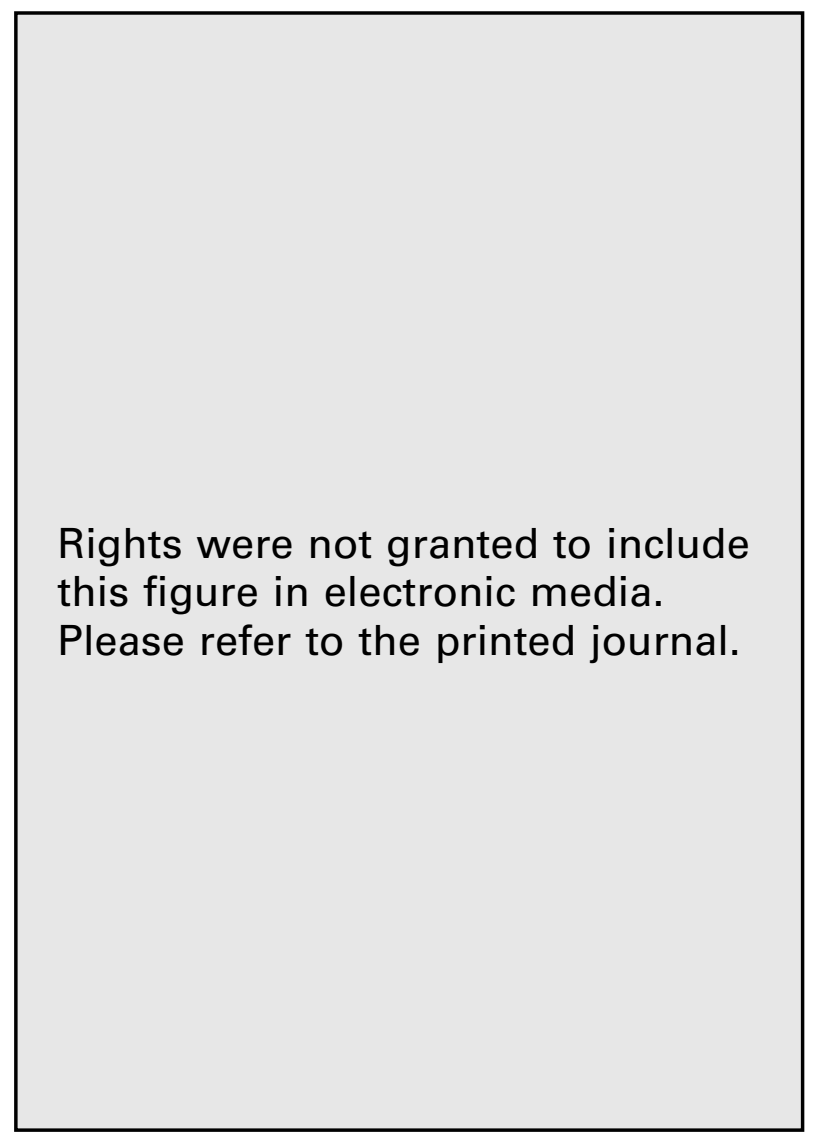

Figure 8. Royal Library, Windsor 12281r. Anatomical studies of the principal organs and arterial system of a female torso, pricked for transfer. This most famous of the Leonardo drawings seems to show many different structures represented in different ways. There also appears to be a combination of ungulate and human anatomy, particularly with reference to the head and neck vessels and the pelvic structures. (The Royal Collection ${ }^{\odot}$ 2004, Her Majesty Queen Elizabeth II; photographer: A.C. Cooper, Ltd.)

clearly shown, as is the relationship between the mitral and aortic valves (Figure 9).

Leonardo held the view, based on classical ideology, that everything in the cosmos was interrelated. In other words, everything from the earth itself, including animal, plant life, and man, to the stars in the heavens were inextricably linked. ${ }^{20}$ Therefore, it was completely natural for him to study animal and human anatomy with the same intensity. Indeed, his observations and deductions derived from animal studies are no less relevant than those derived from his human studies. It is likely that the exaggerated anatomy of the heart of the ox compared with that of man, for example, may have helped him with some of his conclusions. For example, in Windsor 19080r there is a beautiful, simple line drawing of a basal, or strut, cord of the mitral valve amongst other drawings of the valve, which from the shape and size of the papillary muscles is taken from examining an ox heart

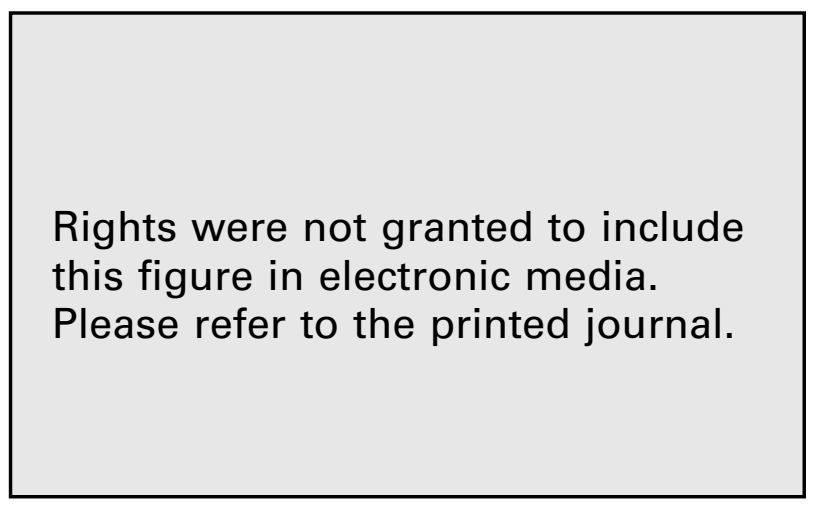

Figure 9. Royal Library, Windsor 19080r (detail). Studies of the heart. Pen and ink on blue paper. A page of drawings showing (1) at the top left the incisons that Leonardo used to open the heart accompanied by a small sketch showing a dissection of the coronary arteries, (2) the papillary muscles and chordae tendineae, and (3) the relationship of the valves to each other. The small drawing at the bottom of this page shows not only the deep scalloping of the posterior leaflet of the mitral valve but also its relationship to all of the valves at the base of the heart. (The Royal Collection ${ }^{\circ}$ 2004, Her Majesty Queen Elizabeth II; photographer: A.C. Cooper Ltd.)

(Figure 10). Although this drawing is quite slight compared with others on the page, he clearly had seen something important about it as he singled it out for separate representation. We now recognize the importance of these tertiary cords because sophisticated imaging has shown that they are the one set of cords that are tensioned throughout the cardiac cycle. It is therefore likely that they have a vital role in supporting left ventricular geometry and function.

The fact that there is mixed species anatomy illustrated in these drawings removes some of the criticisms of accuracy aimed at his anatomy, as the differences are partly accountable by the natural differences between species. This is particularly obvious in his drawing of the papillary muscles of the ventricle, which look impossibly pronounced in Windsor drawing 19080r, but which are actually very accurate.

\section{Leonardo and the Aortic Valve}

Within the philosophy of the regressus it is possible to identify reasoning methods by which he may have worked out the details of the aortic valve closure mechanism. Applying his knowledge of hydrodynamics and the fact that flowing fluid columns were affected by fluid drag close to the walls of the vessel, which in turn creates nonlaminar flow, he was able to look at the shape of the aortic root and deduce that the closure of the valve began in late systole as a result of increasing pressure behind the valve leaflets created by vortices in the sinuses of Valsalva. In the context of the regressus this would be the reasoned fact. There are 


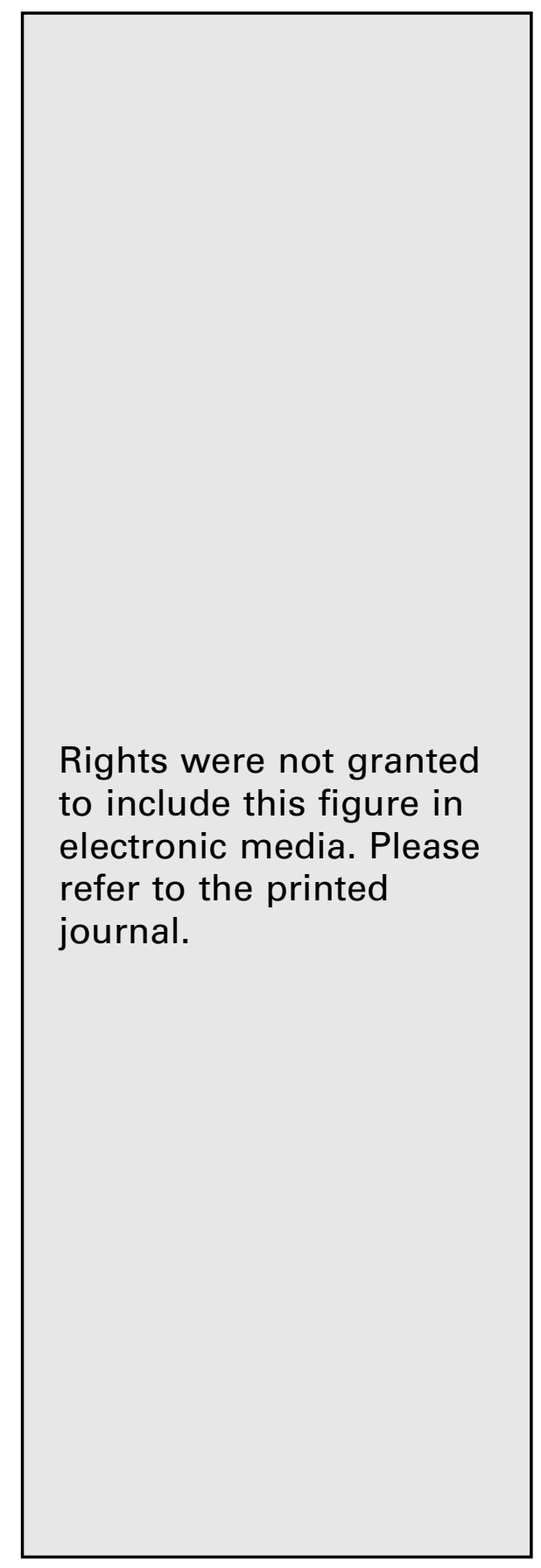

Figure 10. Royal Library, Windsor 19080r (details). Studies of the heart. A, This part of the drawing shows the profile of the papillary muscles of the mitral valve of an ox. The very architectural nature of this drawing corresponds to Leonardo's comparisons between the human body and architectural design. B, This drawing beautifully illustrates the importance of what we now refer to as the basal or strut cord of the mitral valve, antedating modern appreciation of its importance in left ventricular architecture and function. (The Royal Collection $\odot$ 2004, Her Majesty Queen Elizabeth II; A.C. Cooper Ltd.)

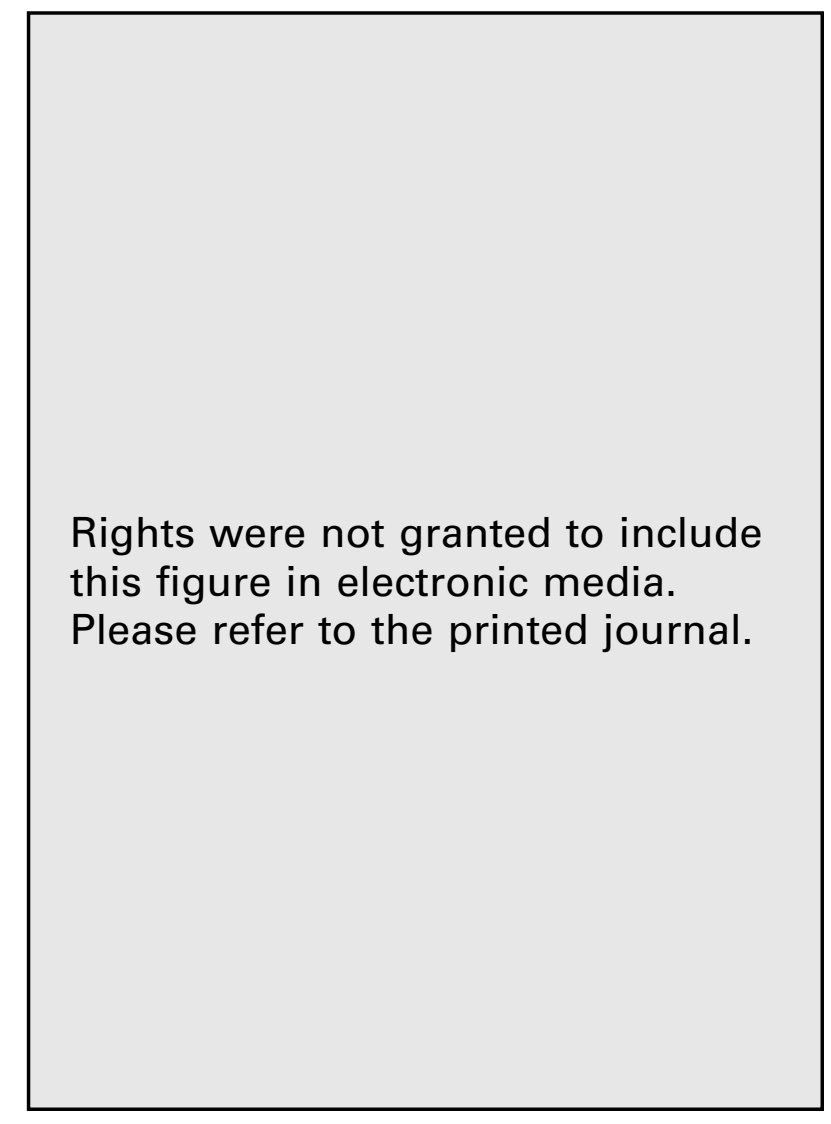

Figure 11. Royal Library, Windsor 19083v. Studies of the vortex motion of blood within the heart. Pen and ink on blue paper. Multiple drawings of vortices in the blood, examining their part in the closure mechanism of the aortic valve. In part of the accompanying note he states that "the wave of blood which drives through it proceeds with the opposite motion, (opposite to regurgitation), throughout the entire artery." Why did he not go on from this to perceive the circulation as we now know it? (The Royal Collection ${ }^{\odot}$ 2004, Her Majesty Queen Elizabeth II; photographer: A.C. Cooper Ltd.)

many drawings, particularly in the Codex Leicester, illustrating vortices in the flow of water in a variety of circumstances. Simply by looking at the shape of the aortic root he was able to deduce the impact of its form on the blood flow through that area (Figure 11).

He then proceeded to describe an experiment to prove this hypothesis. This would equate to the observed fact in the context of deductive reasoning. It is enlightening to relive this brilliant piece of work through his words. He made it absolutely clear that the reflux of blood back toward the ventricle alone cannot be the force that closes the valve, and he produced a drawing (Figure 12) to demonstrate this point. All cardiac surgeons will know this phenomenon when the valve is "tripped" open during the infusion of antegrade aortic cardioplegia. 
Rights were not granted to include this figure in electronic media. Please refer to the printed journal.

Figure 12. Royal Library, Windsor 19082r (detail). Studies of the heart. Pen and ink on blue paper. Small sketch to show what would happen if aortic valve closure depended simply on the reflux of the blood. This emphasizes the importance of the vortices in the sinuses of "Leonardo" to close the valve. (The Royal Collection ${ }^{\odot}$ 2004, Her Majesty Queen Elizabeth II.)

How the blood which turns back when the heart reopens is not that which closes the valves of the heart. This would be impossible because if the blood beat against the valves of the heart while they are corrugated, wrinkled and folded, the blood which presses from above, would weigh and press down the front of the membrane upon its origin, as is shown at the valve " $r$ ", "o" [in the figure], the folds of which, being weighted down from above, would close in solid contact, whereas Nature intended it to be stretched in height and width.

\section{Windsor 19082 $r^{21}$ (Figure 13)}

He explained, "that when the heart contracts, blood from the lower ventricle rushes with impetus through the cusps of the aortic valve, then forms a vortex that grows against the walls of the sinus and valve leaflets."

In a remarkable piece of writing, Leonardo described the formation of vortices as if he were observing them in action. He wrote, "the middle of the blood stream which surges through the triangle 'a b c,' (the valve orifice) surges to a much greater height than that which surges along the sides." This is describing laminar and nonlaminar flow. He went on to say,

This occurs so that the blood in the middle of the triangle directs its impetus straight upwards and that which surges along the sides distributes its impetus by lateral motion, and percusses the front of the arches of the hemicycles, and follows the concavity of this hemicycle, constantly passing downwards, until it percusses against the concavity at the base of this hemicycle \& then by reflected motion turns upward \& continues to revolve upon itself with a circular motion until it expends its impetus.

Windsor $19116 r^{22}$

This passage is describing the vortices in the sinuses of Valsalva. Leonardo wrote extensively about this phenome-

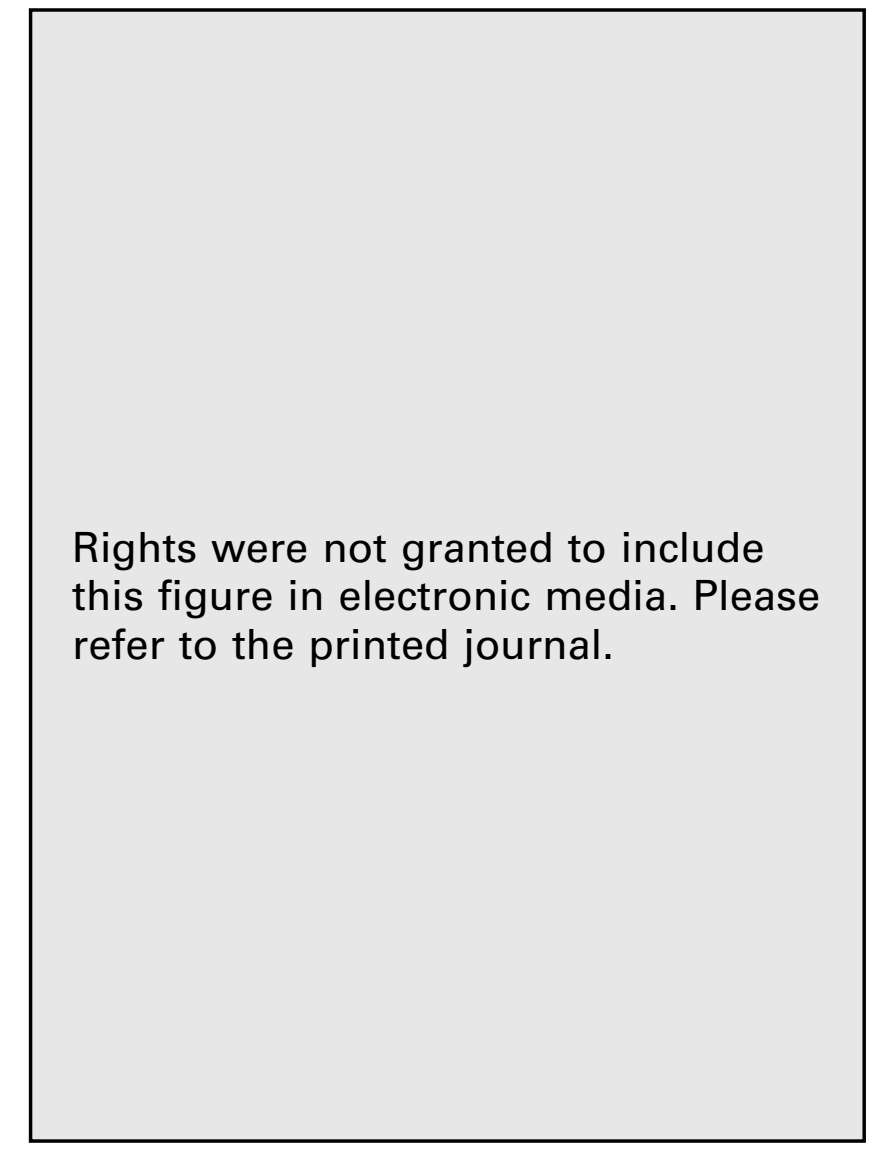

Figure 13. Royal Library, Windsor 19117v. Circulation of the blood. Numerous drawings of a model of the aortic root and valve with further illustrations of the importance of the vortices. The drawing at top right is a beautiful rendering of the open valve leaflets. (The Royal Collection ${ }^{\circledR}$ 2004, Her Majesty Queen Elizabeth II.)

non and called repeatedly on his extensive comprehension of fluid dynamics to support his contentions. This discovery should warrant the renaming of the sinuses of Valsalva to those of Leonardo. It would be a fitting tribute to this wonderful piece of deductive reasoning.

In keeping with his method of proof disproof, Leonardo went on to state, "The adversary states that this part [the aortic valve] ... is of necessity closed when the ventricle re-opens. This takes place because the blood, which descends upon the valve, beats against the valve and presses it shut. The shape of the valves denies this as they would rather be flattened out than shut." Here he is returning to the idea that the closure of the valve cannot be a result of simple reflux of the blood in the aorta. He invokes a teleological argument to support his claim, that the shape of the valve leaflets denies the possibility that valve closure happens as result of simple reflux of the blood. The emphatic way that this proposition is stated and restated makes it irrefutable that he was certain of all of the subtleties of the mechanism 
Rights were not granted to include this figure in electronic media. Please refer to the printed journal.

Figure 14. Royal Library, Windsor 19082r. Studies of the heart. This fascinating page of drawings includes the clay mold for the casting of the glass model of the aortic root (top right), designs for an artificial valve (top left), and the functioning aortic root including the left ventricular outflow tract. (The Royal Collection ${ }^{\circ}$ 2004, Her Majesty Queen Elizabeth II.)

of closure of the aortic valve and the reason for the presence of the aortic sinuses. His intimate arguments with himself, relating the negative side of his argument through an adversary and the positive side through the auditor of the information, recur throughout the notebooks

His desire to understand and know all that was possible, however, did not stop there. He clearly wanted to explain the reason for every deduction as he went on to design an ingenious experiment to prove his hypothesis. He described the making of a glass model to replicate the normal aortic root. He stated, "A plaster mould to be blown with thin glass inside and then break it from head to foot at 'a,' "n"' (Figure 14). Here he was describing the method by which a model of the aortic root and sinuses could be made. He then turned his attentions to what must be the first proposition for the fabrication of a prosthetic heart valve. He instructed as follows, "but first pour wax into this valve of a bull's heart so that you may see the true shape of this valve." Here he acknowledges the need to stretch out the leaflets so that their true shape will be rendered accurately. There are several drawings at the top left hand side of this page of the manuscript (Windsor 19082r) that look as if they relate to the design of a prosthetic valve for use in the root of the aorta replicated in glass.

His text continued to describe the experiment itself. "Make this test in the glass [model] and move inside it water and panic grass seed" (Figure 15). In other words, create a circulation with water across the valve and aortic root and by introducing grass seeds one will be able to track the vortices within the sinuses and so the closing force on the aortic surface of the leaflets, thus proving his hypothesis. This model was reproduced in the laboratory by Gharib and associates. $^{23}$ Whether or not Leonardo produced such a model remains open to question. As one reads his detailed notes on the formation of vortices, however, the voice of the historical record contained within them very strongly suggests a far more than teleological argument behind his forceful description of the phenomena involved. The demonstration of this phenomenon in vivo has only been possible with modern technology in the past few years.

\section{The Expansile Properties of the Aortic Root}

Leonardo went on to describe the finding that the aortic root is a very elastic structure and as a result is able to absorb energy. He also identified that the aortic valve leaflets are part of the aortic wall. He explained the reason why this is important for the normal function of this complex anatomical structure. He related these findings to why the valve is able to continue to function over many years without being torn apart by the forces exerted on it. He wrote of the importance of the mechanism for the absorption of the energy from the recoil of the blood "... the valves are constructed in association with the vessels immediately at the termination of the heart. This was ordained by their author so that the reflected blood with its momentum might not tear away the membranes of which these valves are composed" (Windsor 19118r). ${ }^{24}$

Leonardo then followed this with a direct statement as to why it is essential for this structure to be elastic. He continued in the same passage, ". . . this momentum, seeing that it must expand in the membranes at the base of the vessels, does no damage to these valves, but is cast horizontally to beat against and expand with ease the tunics of the blood (vessels) in which the aforesaid momentum is expanded." These ideas antedate by over half a millennium the physiological arguments for stentless valve technology.

\section{The Circulation}

Nowhere in the notebooks of Leonardo is there a description of the circulation as described by William Harvey in "De Motu Cordis," nor have there been any claims that he had moved on from the Galenic thoughts on the flux and reflux 
of blood across the membranous septum. This "percussion of the blood," as he described it, is associated with the heating of the blood and the dissipation of that heat through the lungs, which was their primary function. However, there are passages in the notebooks that do imply local circulations, which are worth considering as important first steps toward a fuller understanding.

He observed that the contraction of the ventricle corresponds to the timing of the peripheral pulse. He stated:

The same thing happens in the body of animals by means of the beating of the heart, which generates a wave of blood through all of the vessels, which continually dilate, and contract. The dilatation occurs on the reception of the superabundant blood, and the contraction is due to the departure of the superabundance of the blood received, and the pulse teaches this to us when we touch the aforesaid vessels in any part of the living body with the fingers.

Windsor 19045r. c.1513

If that statement is taken in conjunction with the one that follows, in which he returned to his vast knowledge of hydrodynamics and noted that, "the movement of liquid made from one direction, proceeds in the original direction as long as the force remains in it which was given to it by its first mover" (Windsor 19045r. c.1513), it is only a short deductive step to the suggestion of the circulation around the body. This step so far has not been found in his work. It is interesting to note that William Harvey had considerable difficulty convincing his academic colleagues of the time that the circulation was a reasonable proposition and met with stiff resistance to the acceptance of the hypothesis. ${ }^{25}$ In another part of the notebooks Leonardo considered the renal circulation. He wrote, "The quantity of urine shows the quantity of blood which is produced and goes to the kidneys but first passes through the opening of the heart" (Windsor 19069r c. 1504-1509). ${ }^{26}$ This wonderful piece of deductive reasoning is exactly the information we use on a daily basis in the simple evaluation of cardiac output in many clinical scenarios. At the very least it demonstrates that Leonardo understood that blood did leave the heart and perfuse the kidneys. Again, it is difficult to accept that a man of such immense intellect could not take that last step to deduce the total circulation of the body.

A further passage invoking the description of a local circulation is that of the pulmonary circulation. Here he writes as follows, "This part [of the blood] unobstructed, gives with its principal wave due nourishment to the vessels of the lung when, after being refreshed in the lung, it returns in large part to refresh the blood which was previously in the left ventricle where it divided" (Windsor 19074r c. 1513). ${ }^{27}$ Note the reference to the blood dividing. Again he is returning to the Galenic idea of the blood passing across the septum to and fro.

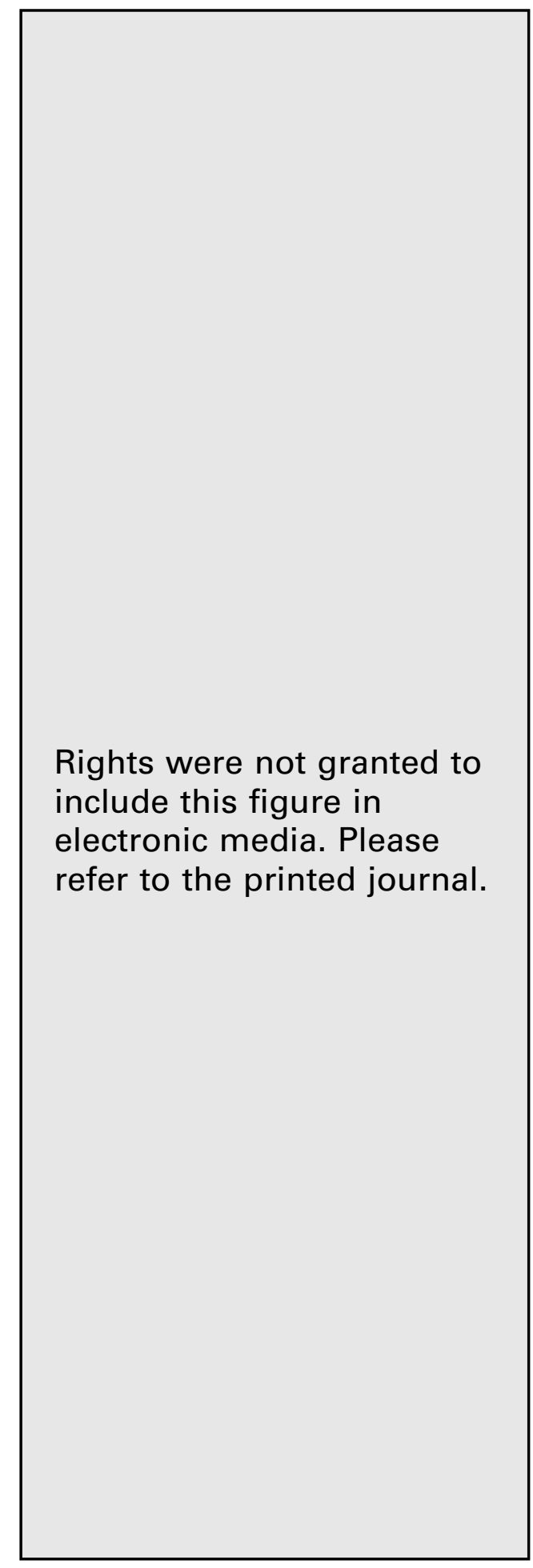

Figure 15. Royal Library, Windsor 19082r (details). Studies of the heart. A, The model for the casting of the aortic root. B, Note the mitral valve as well as the beautiful rendering of the aortic root and left ventricular outflow tract. In the note in this portion of the drawing Leonardo likens the closure mechanism of the mitral valve, with the wind in the sail of a ship. (The Royal Collection ${ }^{\odot}$ 2004, Her Majesty Queen Elizabeth II.) 


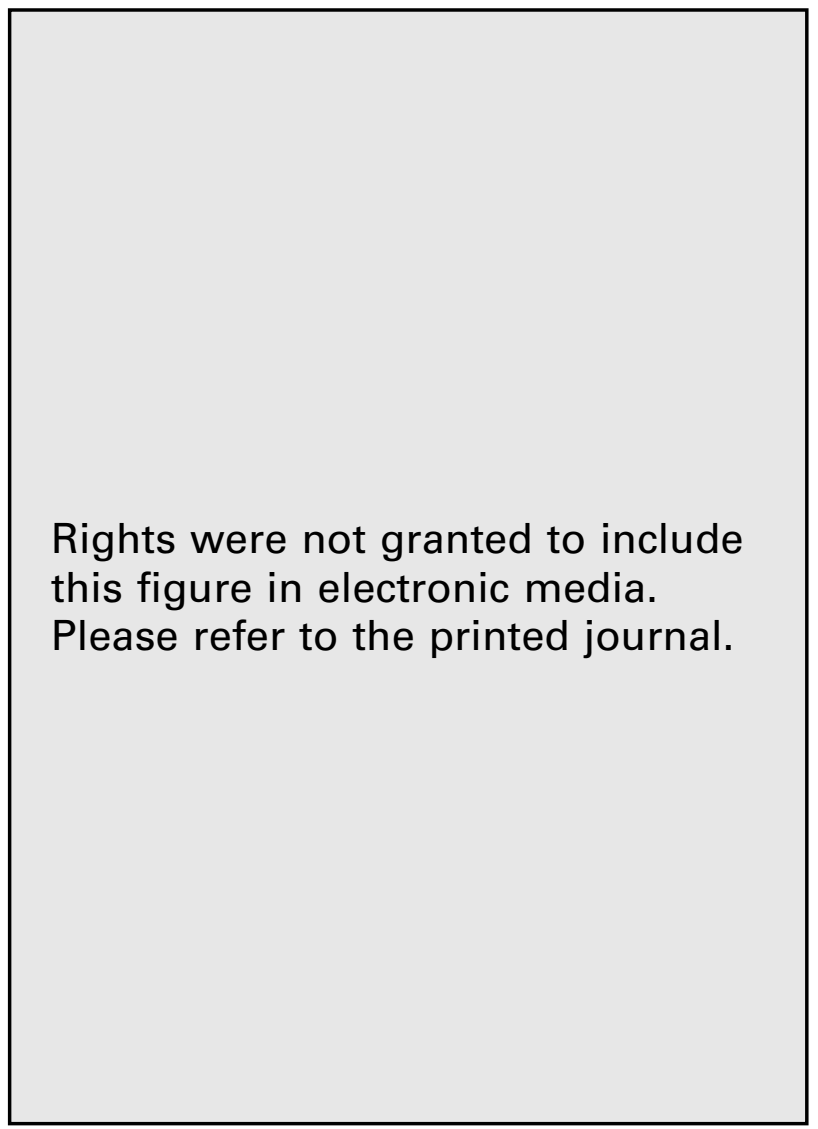

Figure 16. Royal Library, Windsor 19071r. Heart ca. 1513. Pen and ink on blue paper. $0 x$ heart from the posterior view showing the dissected bronchial arteries and their relationship to the airways. This is one of his later drawings and demonstrates Leonardo's departure from written tradition and complete reliance on his own observations. What is most remarkable about this illustration is that it is the first report and illustration of the paired bronchial arteries and their importance for the nourishment of the bronchi separate from the pulmonary artery and pulmonary parenchyma. (The Royal Collection $\odot$ 2004, Her Majesty Queen Elizabeth II; photographer: EZM.)

In another part of the notebooks Leonardo beautifully described the bronchial circulation as being necessarily separate from the pulmonary circulation and clearly described, and indeed drew (Windsor 19071r), the paired bronchial arteries (Figure 16). He stated:

You have to consider the second order [ie, pulmonary] of veins and arteries which cover the first [ie, bronchial] veins and arteries which nourish and vivify the trachea, ... and why in such an instrument did nature duplicate artery and vein, one upon the other, finding themselves for the nourishment of one and the same member.... She [ie, Nature] gave such [bronchial] veins and arteries to the trachea as were needed for its life and nourishment, and separated a little from the Trachea the other large \{Pulmonary $\}$ branches to nourish the substance of the lung with greater convenience. $^{28}$

These observations remain pertinent today and relevant in lung transplantation. It is interesting to speculate whether his use of comparative anatomy, in this case the ox, may have enhanced his ability to identify these otherwise small structures and to ascribe to them the importance that he clearly described.

William Harvey may have been the first to establish the full description of the circulation in print. It is interesting to note, however, that the two men had held overlapping ideas in the genesis of this hypothesis. Both men identified that the timing of the pulse was linked to ventricular contraction. Both men developed the Galenic thought that the blood vessels could be compared with a dicotyledonous plant. Galen suggested that the liver could be likened to a seed and the inferior vena cava and its tributaries to the roots of a plant. Similarly the superior vena cava and its branches he likened to the stem and its branches. Leonardo took things further and emphatically stated that all vessels grew from the heart and not the liver, and that the heart was the seed. He said, "All vessels arise from the heart. The reason for this is that the maximum thickness found in the veins and arteries occurs at the junction with the heart. The more removed they are from the heart the thinner they become and divide into smaller branches"29 (Windsor 19028r) (Figure 17).

These few examples of Leonardo's investigations of the heart and the circulation serve to show the meticulous way he observed, considered, and recorded his work. How much of his original work has been lost we shall never know, but the quality exhibited in what survives indicates the seriousness and respect with which it should be read and revisited.

\section{Leonardo and Physicians}

Finally, it is amusing to note Leonardo's attitude toward the medical profession of the day. He wrote, "Endeavor to preserve thy health in which thou wilt succeed the better the more thou guardest thyself from the physicians. For their mixtures are a kind of alchemy on which there are no fewer books than there are remedies" (WindsorAn. III XXV). ${ }^{30}$ In this short comment he demonstrates not only his suspicion of the medical profession of the day, but also the importance that he placed on prevention of illness through a healthy lifestyle.

\section{Conclusions}

Recognition of his academic achievements was clearly important to Leonardo. His paraphrasing of Dante indicates this: "He who, without Fame, burns his life to waste leaves no more vestige of himself on earth than wind-blown smoke, or foam upon the water." ${ }^{31}$ And yet he published 
none of his anatomical works. Organizing his manuscripts for publication was a priority for him. He wrote the following memorandum c.1507-1509 (Windsor 19070v): "Have your books on Anatomy bound." His first and last wishes with regard to publication of his vast output were for his anatomical works. Sadly, this never happened. Leonardo bequeathed all of his notebooks and most of his other belongings to his pupil Melzi, whom he charged with organizing the vast quantity of work; the work lay fallow. Although Melzi never carried out his master's wishes, the manuscripts were known and sought after by great collectors. However, their true scientific worth was never recognized, whilst the beauty, which lay in the drawings, was revered. For this we have to be thankful, as that has resulted in the preservation of these priceless artifacts to the present day.

It is commonly suggested that Leonardo da Vinci was mercurial in not finishing much of what he took on, that he might have been disorganized and lacking in focus. Clearly he experienced difficulties in relating to some of the academics of the time and may have been intellectually unsupported. He certainly was disadvantaged by lack of a formal education. However, some of this may have worked to his advantage in allowing him the opportunity of exercising a giant open mind in a way that may have been impossible if constrained by formal teaching and the constraints of a formal academic environment.

He was certainly a man of great industry and a powerful thinker who had phenomenal deductive powers and an unlimited thirst for true knowledge. He has left us a great legacy of art and science and, perhaps most important, scientific method. The following simple truths shout out from every page of his work and can be taken up by all of us involved in a scientific endeavor today. They are, keep an open mind, think laterally, and question everything repeatedly. Use all relevant science and knowledge, from any source that may inform on a problem, and above all do not just look but look and "see!" These simple messages across time truly are a paradigm for modern clinical research.

\section{Coda}

Finally, let this fable by Leonardo act as a warning to all of us who may be tempted to rush to use new technology on our patients without first gathering the necessary data and drawing the appropriate conclusions:

The vain and wandering butterfly, not content with being able to fly at its ease through the air, overcome by the tempting flame of the candle, decided to fly into it; but its sportive impulse was the cause of a sudden fall, for its delicate wings were burnt in the flame. And the hapless butterfly having dropped, all scorched, at the foot of the candlestick, after much lamentation and repentance, dried tears from its

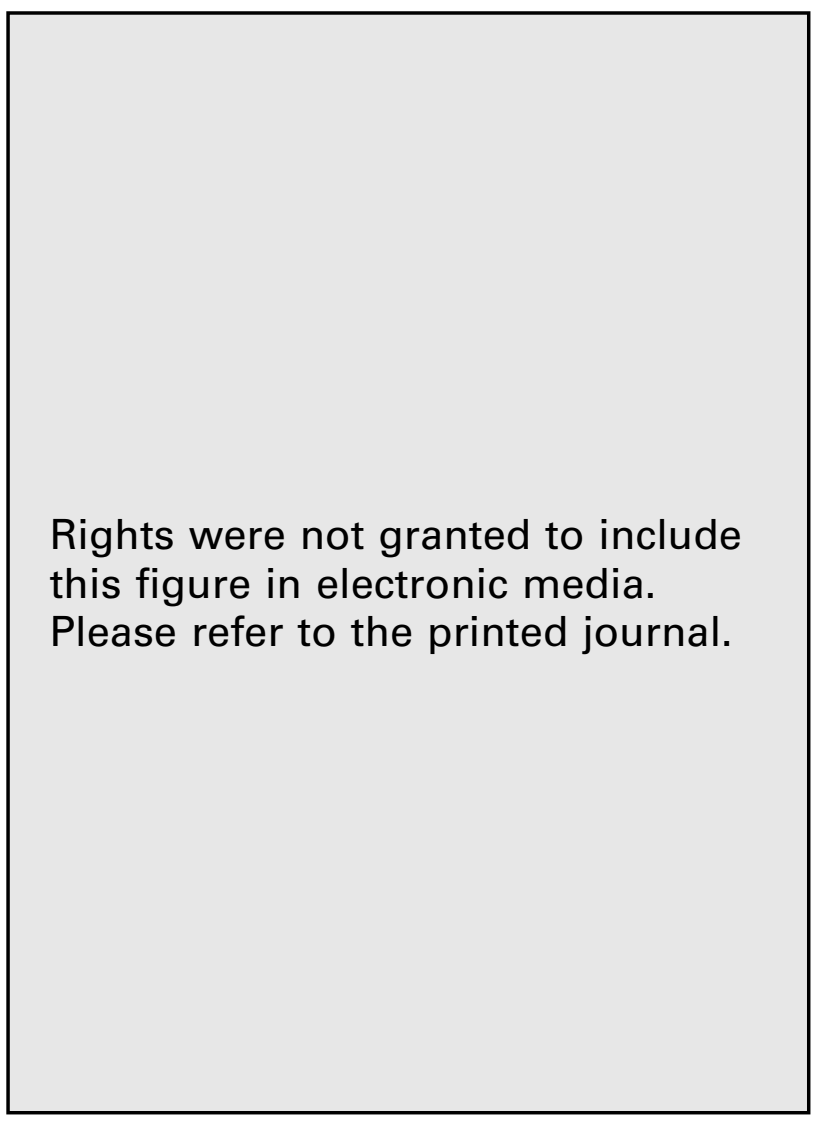

Figure 17. Royal Library, Windsor 19028r. The main arteries and veins of the thorax and studies of the heart and blood vessels compared with a plant sprouting from a seed. (The Royal Collection ${ }^{\odot}$ 2004, Her Majesty Queen Elizabeth II; photographer: A.C. Cooper Ltd.)

swimming eyes, and raising its face exclaimed: "O false light! How many must thou have miserably deceived in the past, like me; or if I must indeed see light so near, ought I not to have known the sun from the false glare of dirty tallow?"32

Codex Atlanticus 66a; 200a

\section{References}

1. Codex Atlanticus, 115a. Richter J-P. The notebooks of Leonardo da Vinci. Compiled and edited from the original manuscripts. New York: Dover Publications; 1883 (reprinted 1970). Vol I, p.15.

2. Vasari G. Lives of the painters, sculptors and architects. East Rutherford (NJ): Penguin Group (USA) Inc; 1987. p. 255.

3. Marani P. Leonardo da Vinci. New York: Abrams; 2000. p. 62.

4. Vasari, op cit. p.258.

5. O'Malley C, Saunders J. Leonardo da Vinci on the human body. New York: Dover; 2003. p.17.

6. Marani, op cit. p. 12.

7. O'Malley and Saunders, op cit. p. 238.

8. Kemp M. The marvellous works of nature and man. London: J. M. Dent \& Sons; 1981. p. 293.

9. Richter, op cit. Vol II, p. 290.

10. O'Malley and Saunders, op cit. p. 300. 
11. O'Malley and Saunders, p. 302.

12. Kemp M. Dr. William Hunter on the Windsor Leonardos and his volume of drawings attributed to Pietro da Cortona. The Burlington Magazine. 1976, vol. 118, p.144.

13. Hutton R. Surgical research or comic opera: questions, but few answers. Lancet. 1996;347:984.

14. Zubov VP. Leonardo da Vinci. Kraus DH, translator. Cambridge (MA): Harvard University Press; 1968. p.101-5.

15. Kemp, op cit., p.161.

16. The Cambridge history of Renaissance philosophy. Scmitt CB, Skinner Q, editors. Cambridge (UK): Cambridge University Press; 1988. p. 690.

17. Zwijnenberg R. The writings and drawings of Leonardo da Vinci: order and chaos in early modern thought. Cambridge (UK): Cambridge University Press; 1999. p. 153.

18. Richter, op cit. Vol. II, p.107.
19. O'Malley and Saunders, op cit. p. 394.

20. Kemp, op. cit. p. 114-8.

21. O'Malley and Saunders, op cit. p. 264.

22. O'Malley and Saunders, op cit. p. 268.

23. Gharib M, Kremers D, Koochesfahani M, Kemp M. Leonardo's vision of flow visualization. Exp Fluids. 2002;33:219-23.

24. O'Malley and Saunders, op cit. p. 260.

25. Harvey W. De motu cordis. 1682.

26. O'Malley and Saunders, op cit. p. 290.

27. O'Malley and Saunders, op cit. p. 256.

28. O'Malley and Saunders, op cit. p. 394.

29. O'Malley and Saunders, op cit. p. 282.

30. Richter, op cit. Vol. II, p. 133.

31. Alighieri D. The divine comedy, vol I, Inferno, 24:49-51.

32. Richter, op cit. Vol. II, p. 136.

\section{Rights were not granted to include this figure in electronic media. Please refer to the printed journal.}

Royal Library, Windsor 12579r. Left, An old man seated in profile. Right, Four studies of swirling water. (The Royal Collection ${ }^{\circ}$ 2004, Her Majesty Queen Elizabeth II; photographer: A.C. Cooper Ltd.)

Francis C. Wells, Consultant Cardio-thoracic Surgeon at Papworth Hospital in Cambridge and Associate Lecturer in the Department of Surgery in the University of Cambridge, is also Special Consultant on Leonardo's anatomical drawings for the Universal Leonardo Project. Thereza Crowe is Coordinator of the Leonardo Laboratory for the Universal Leonardo Project and a curatorial contributor to its Exhibitions Programme.

The Universal Leonardo Project brings together a series of international exhibitions focusing on the work of Leonardo da
Vinci and the Leonardo Laboratory, a groundbreaking scientific analysis programme.These will be integrated with a Web site and publication and education programmes to create a unique resource of data on the artist, his life, and his work. The Exhibitions Programme, set to begin in the autumn of 2005 and to carry on through 2006, will link museum collections across Europe. The project is funded by the Council of Europe and is coordinated by the Universal Leonardo Bureau in London. For more information call ++442075148861 or E-mail infoULB@ csm.linst.ac.uk. 